http://www.jfas.info

\title{
EFFECTS OF PALM POLLEN ON FOLLICULOGENESIS PROCESS AFTER TREATMENT WITH CYCLOPHOSPHAMIDE AMONG RATS
}

\author{
H. K. Jashni and H. K. Jahromi \\ Research center for non.Communicable Diseases, Jahrom University of Medical \\ Sciences, Jahrom, Iran
}

Published online: 15 June 2016

\begin{abstract}
Background and purpose: Palm pollen is a good source of natural antioxidants and has a high level of health benefits and nutritional value. The purpose of this study was to investigate effects of palm pollen on folliculogenesis process after treatment with cyclophosphamide among rats.

Materials and Methods: This experimental study conducted on 48 adult female Wistar rats. The mice were randomly divided into 6 groups. The control group was kept without receiving any material and in normal conditions until the end of experiment. The group with cyclophosphamide of $150 \mathrm{mg}$ per $\mathrm{kg}$ body weight received it intraperitoneally. Experimental groups 1 and 2 received palm pollen extract daily and orally with doses of 200 and $400 \mathrm{mg}$ per kg body weight.

Experimental groups 3 and 4 received palm pollen daily and orally with doses of 200 and 400 mg per $\mathrm{kg}$ body weight along with $150 \mathrm{mg}$ per $\mathrm{kg}$ body weight cyclophosphamide intraperitoneally. Blood samples were taken from all the groups at the end of fourth week and after anesthesia.
\end{abstract}

Author Correspondence, e-mail: hossein.kargarjahromy@yahoo.com doi: http://dx.doi.org/10.4314/jfas.v8i2s.137 
The blood serum was isolated and sent to the laboratory for measuring serum concentrations of the hormones estrogen and progesterone. The ovaries also were examined after weighing and tissue cutting via a light microscope.

Findings: The average weight of ovaries as well as the number of secondary and graafian follicles in the cyclophosphamide group indicated a significant decrease compared to the control group. However, the average weight of ovaries as well as the number of secondary and graafian follicles in experimental groups 1,2, 3 and 4 revealed a significant increase than the cyclophosphamide group $(\mathrm{p}<0.05)$. Average serum concentrations of hormones estrogen and progesterone in the group receiving cyclophosphamide decreased significantly compared to the control group. But, serum concentrations of estrogen in experimental groups 1, 2, 3 and 4 and the average of progesterone in the experimental groups 1 and 2 increased significantly compared to the cyclophosphamide group ( $\mathrm{p}<0.05)$.

Conclusion: According to the results of this study, aqueous extract of pal pollen has improved cyclophosphamide damaging effects on the folliculogenesis process among rats.

Keywords: palm pollen. cyclophosphamide. folliculogenesis, rat.

\section{INTRODUCTION}

Cyclophosphamide is widely used as an anticancer drug and a weakening agent of the immune system in organ transplantation (1). Despite the effectiveness of this drug in the treatment of various cancers, it entails numerous side effects including impaired reproductive system dysfunction in both males and females (2 and 3). Fertility disorders, amenorrhea, increasing the number of atretic follicles and decreasing plasma levels of estrogen and progesterone are the side effects of cyclophosphamide among females (4 and 5). Like other drugs used in chemotherapy, cyclophosphamide devastating effects occur through the induction of oxidative stress and the increase of free radicals level in the body (5).

Due to high efficiency and low side effects, medicinal herbs from ancient times until now are widely used for prevention and treatment of various diseases throughout the world (6). Palm tree (Phoenix dactylifera L.) is a family of Arecacea planted in most tropical areas of the world. Various sectors of the tree such as palm leaf, root, fruit, seed, dactylifera, cores and 
pollen have many health benefits including properties of anti-cancer, antioxidant, anti-inflammatory, anti-diabetic, lowering blood pressure, anti-fungal and liver protective (7 and 8). Palm pollen is a good source of natural antioxidants with high levels of therapeutic properties and nutritional value. Estrone, sterols, estradiol, flavonoid, saponin, selenium zinc, calcium, potassium, vitamins A, B and C are compounds of palm pollen (9 and 10).

In traditional medicine, pollen is known as an effective drug for treatment of infertility in both males and females (11). In addition, numerous studies on the effects of pollen distillate on females' reproductive physiology have shown that pollen has estrogenic effects and leads to the increase of the folliculogenesis process among rats (12 and 13). Researchers believe that effects of ovarian stimulation by palm pollen are associated with the presence of compounds such as glycosides flavonoids, saponins, alkaloids and steroidal compounds (12 and 13).

Therefore, due to the antioxidant properties as well as the positive effects of palm pollen on females' reproductive physiology, the present study was done to investigate the protective effects of palm pollen on cyclophosphamide side effects on ovarian tissue and ovarian hormone levels.

\section{MATERIALS AND METHODS}

In this experimental study, 48 healthy and adult female rats with the age range of 3-2 months and the weight range of 170-150 grams were tested. During the experiment, the mice were kept in conditions of 12 hours of light and 12 hours of darkness. In order to adapt to the environment they were kept for a week and then were randomly divided into 6 groups.

The first group (control) used enough intensive food and water without any restrictions during testing. Cyclophosphamide group received cyclophosphamide intraperitoneally with a dose of $150 \mathrm{mg}$ per kg body weight. Experimental groups 1 and 2 received aqueous extract of palm pollen daily and orally with doses of 200 and $400 \mathrm{mg}$ per $\mathrm{kg}$ body weight (12 and 13). The experimental group 3 received aqueous extract of palm pollen orally with a dose of $200 \mathrm{mg}$ per $\mathrm{kg}$ body weight along with $150 \mathrm{mg}$ per $\mathrm{kg}$ body weight of cyclophosphamide intraperitoneally. The experimental group 4, received aqueous extract of palm pollen orally 
with a dose of $400 \mathrm{mg}$ per $\mathrm{kg}$ body weight along with150 $\mathrm{mg}$ per $\mathrm{kg}$ body weight of cyclophosphamide intraperitoneally.

Blood samples were taken from all groups at the end of fourth week and after anesthesia. The blood serum was isolated and sent to the laboratory for measuring serum concentrations of the hormones estrogen and progesterone. After dissection, ovaries were removed, weighed and placed in $10 \%$ formalin and sent to the laboratory for preparation of tissue sections. After casting, 5m serial tissue sections were prepared and examined under a light microscope using a 3-field scaled graticule of each slide. The number of primordial, primary, secondary follicles as well as count and average graafian were calculated.

One way variance analysis (ANOVA) was used for analyzing the data. Statistical analysis was carried out using SPSS software and the significance level was assumed $(\mathrm{p}<0.05)$. The data were calculated and compared in the results section as Mean \pm SEM.

\section{FINDINGS}

Based on the results presented in Table 1, the average weight of the ovaries in the cyclophosphamide group was decreased compared to the control group $(\mathrm{p}<0.05)$. But, it increased significantly in groups 1, 2, 3 and 4 compared to the cyclophosphamide group $(\mathrm{p}<0.05)$.

The average number of secondary and graafian follicles in the cyclophosphamide group showed a significant reduction than the control group $(\mathrm{p}<0.05)$.The average number of primary follicles indicated a significant growth compared to cyclophosphamide group only in experimental group 2. The average of secondary follicles number in groups 2, 3 and 4 showed a significant increase compared to the cyclophosphamide group. In addition, the average number of graafian follicles in the experimental groups 1,2,3 and 4 increased significantly compared to the cyclophosphamide group $(\mathrm{p}<0.05)$.

According to the results presented in table 2, the serum concentration of hormones estrogen and progesterone in the cyclophosphamide group was significantly reduced compared to the control group $(\mathrm{p}<0.05)$. However, the average of estrogen in experimental groups $1,2,3$ and 4 increased significantly compared to the cyclophosphamide group $(\mathrm{p}<0.05)$. The average of 
hormone progesterone in experimental groups 1 and 2 increased significantly compared to the cyclophosphamide group $(\mathrm{p}<0.05)$.

Table 1. Average weight and number of ovarian follicles in different experimental groups

\begin{tabular}{|c|c|c|c|c|c|}
\hline Variable & Ovarian weight & Average & Average number & Average & Average \\
\hline & \multirow[t]{3}{*}{ (gram) } & number of & of primary & number of & number of \\
\hline \multirow[t]{2}{*}{ Groups } & & primordial & follicles & secondary & graafian \\
\hline & & follicles & & follicles & follicles \\
\hline Control group & $0.037 \pm 0.002$ & $6.92 \pm 0.18$ & $3.03 \pm 0.15$ & $5.8 \pm 0.31$ & $2.27 \pm 0.21$ \\
\hline Cyclophosphamide group & $0.025 \pm 0.002 *$ & $6.24 \pm 0.4$ & $3 \pm .37$ & $3.72 \pm 0.44 *$ & $1.28 \pm 0.12 *$ \\
\hline Experimental group 1 & $0.039 \pm 0.002$ & $6.77 \pm 0.52$ & $2.98 \pm .22$ & $4.85 \pm 0.52$ & $1.75 \pm 0.25$ \\
\hline \multicolumn{6}{|l|}{ (palm pollen extract } \\
\hline \multicolumn{6}{|l|}{$200 \mathrm{mg} / \mathrm{kg})$} \\
\hline Experimental group 2 & $0.04 \pm 0.001$ & $6.96 \pm .04$ & $3.96 \pm 0.43$ & $5.91 \pm 0.35$ & $2.16 \pm 0.19$ \\
\hline \multicolumn{6}{|l|}{ (palm pollen extract } \\
\hline \multicolumn{6}{|l|}{$400 \mathrm{mg} / \mathrm{kg})$} \\
\hline Experimental group 3 & $0.034 \pm 0.001$ & $6.45 \pm 0.33$ & $3.33 \pm 0.26$ & $4.36 \pm 0.30$ & $2.24 \pm 0.23$ \\
\hline \multicolumn{6}{|l|}{ (cyclophosphamide+ palm } \\
\hline \multicolumn{6}{|l|}{ pollen extract $200 \mathrm{mg} / \mathrm{kg}$ ) } \\
\hline Experimental group 4 & $0.031 \pm 0.002$ & $5.9 \pm 0.31$ & $2.71 \pm 0.37$ & $5.57 \pm 0.19$ & $2 \pm 0.1$ \\
\hline \multicolumn{6}{|l|}{ (cyclophosphamide+ palm } \\
\hline pollen extract $400 \mathrm{mg} / \mathrm{kg}$ ) & & & & & \\
\hline
\end{tabular}

- Averages have been presented as Mean \pm SEM.

- $\mathrm{p}<0.05$ has been considered statistically significant.

- Asterisks represent a significant difference between the control group and other groups.

Table 2. Average of the serum concentration of the hormones estrogen and progesterone

$\underbrace{\text { Variables }}_{\text {Groups }} \begin{array}{ccc}\text { Estrogen } \\ \text { Progesterone }\end{array}$




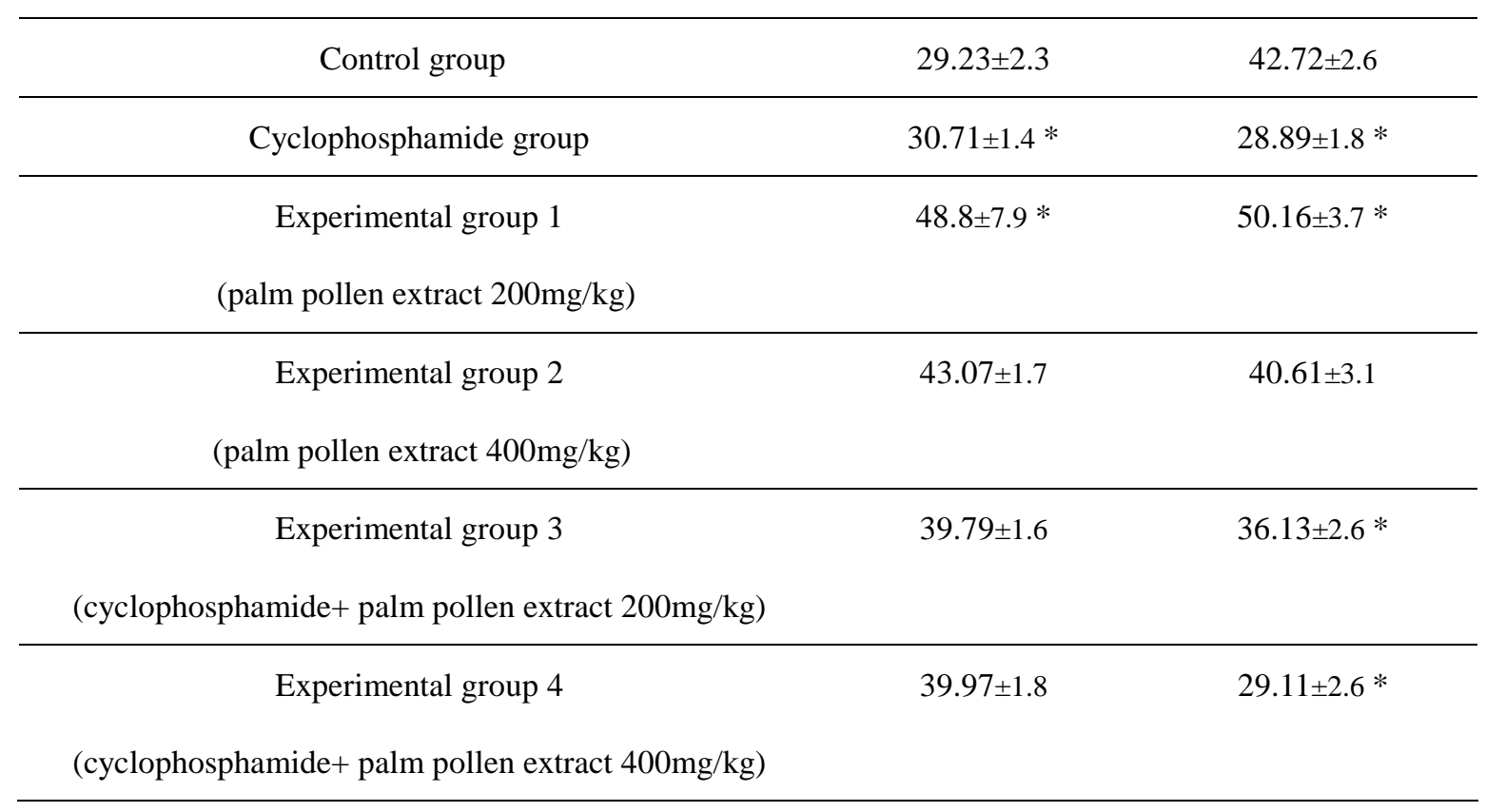

- Averages have been presented as Mean \pm SEM.

- $\mathrm{P}<0.05$ has been considered statistically significant.

- Asterisks represent a significant difference between the control group and other groups.

\section{DISCUSSION}

The results of this study indicate a significant reduction in ovarian weight, ovarian follicles number and estrogen and progesterone hormones with increasing the number of atretic follicles in the groups receiving cyclophosphamide compared to the control group. The results showed a decline in the folliculogenesis and steroidogenesis processes among rats receiving cyclophosphamide which is consistent with the findings of other researchers (4 and 5).

Increase of total ovarian follicles (primary, secondary and tertiary) and decrease of atretic follicles numbers were observed in groups receiving palm pollen aqueous extract with doses of 200 and $400 \mathrm{mg} / \mathrm{kg}$. This indicated positive effects of this plant on ovarian function improvement. Previous studies have also shown stimulation effects of palm pollen extract on rats' folliculogenesis and steroidogenes. According to the results of Hosseini et al (2014) and Moshfegh et al (2016), palm pollen extract increases ovarian follicles and also estrogen and progesterone ovarian hormones level among rats (13 and 14). Based on these studies, compounds found in palm pollen such as flavonoids, estradiol and alkaloid have estrogen-forming property; thus, palm pollen increases females' fertility (13, 14 and 15). 
In addition, according to the results of this study, palm pollen reduced cyclophosphamide destructive effects on tissue and also decreased ovarian hormones in experimental groups receiving cyclophosphamide and different doses of the extract simultaneously. Production of reactive oxygen species (ROS) and oxidative stress in ovarian granulosa cells and consequently the cells apoptosis are regarded as major mechanisms of cyclophosphamide in females' reproductive disorders (16 and 17).

There are several reports regarding the presence of different antioxidant compounds such as flavonoids, alkaloids, vitamins and minerals in the palm pollen (12 and 18). Moreover, protective effects of palm pollen against damaging elements to the reproductive system of males and females have been studied. The results of the Orabi and Shawky (2014) showed that palm pollen is able to improve males' fertility due to the reduction of malondialdehyde level (MAD) which is one of the main indicators of lipid peroxidation in testicular tissue (19).20).

Hammed et al (2012) revealed that palm pollen improves ovarian function and fertility rate among rats exposed to lead acetate (21). Salek Abdollah et al (2015) found out that palm pollen is able to enhance the maturation of oocytes in IVM technique significantly by reducing oxidative stress. Oxidative stress is one of the major barriers for oocyte maturation technique in vitro maturation (IVM) (22).

\section{CONCLUSION}

According to the results obtained in this research, administration of palm pollen extract in combination with cyclophosphamide can reduce devastating effects of the drug on females' reproductive system. It seems that reduction of cyclophosphamide side effects on ovarian follicles and sex hormones is associated with antioxidant properties of the palm pollen.

\section{ACKNOWLEDGEMENTS}

The present paper has been extracted from a research project approved by Jahrom University of Medical Sciences and Health Services. The authors would like to thank all the staff and 
officials of research deputy and technology deputy of this university who sincerely helped us in the course of this research.

\section{CONFLICT OF INTERESTS}

The authors have no conflicts of interest with regard to the compilation and/or publication of this article.

\section{REFERENCES}

[1] Ilbey YO, Ozbek E, Simsek A, Otunctemur A, Cekmen M, Somay A. Potential chemoprotective effect of melatonin in cyclophosphamide-and cisplatin-induced testicular damage in rats . Fertil Steril 2009;92(3):1124-32.

[2] Meirow D, Assad G, Dor J, Rabinovici J, The Gnrh Antagonist Cetrorelix Reduces Cyclophosphamide- Induced Ovarian Follicular Destruction In Mice. Hum Reprod 2004;19: 1294-9.

[3] Lopez SG, Luderer U. Effects of cyclophosphamide and buthionine sulfoximine on ovarian glutathione and apoptosis. Free Radic Biol Med 2004; 36(11):1366-77.

[4] Hosseini A, Zare S, Ghaderi Pakdel F, Ahmadi A. Effects of Vitamin E and Ginseng Extract on Fertility Changes Induced by Cyclophosphamide in Rats. J Reprod Infertil. 2010;11(4):227-237.

[5] Sarabi B, Hassandokht MR, Hassani ME, Ramak Masumi T. Evaluation of Morphological Characteristics of Iranian Edible Wild Asparagus (Asparagus officinalis L.). Iran J Horticultural Sci 2010; 41: 197-207.

[6] Stajner, N, Bohanee, B and Javornik,B. Genetic Variability of Economically Important Asparagus Species as Revealed by Genome Size Analysis and rDNA ITS Polymorphisms. Plant Science,2002; 162: 931-937.

[7] Al-Snafi A.E.The pharmacological importance of Asparagus officinalis- a review. Journal of Pharmaceutical Biology,2015; 5(2): 93-98.

[8] Khorasani A, Sani W, Philip K, Taha RM and Rafat A. Antioxidant and antibacterial activities of ethanolic extracts of Asparagus officinalis cv. Mary Washington: 
Comparison of in vivo and in vitro grown plant bioactivities. African Journal of Biotechnology, 9(49), 2010, 8460-8466.

[9] Verma SP, Tripathi VC, Das P. Asparagus racemosus leaf extract inhibits growth of UOK 146 renal cell carcinoma cell line: Simultaneous Oncogenic PRCCTFE3 Fusion Transcript Inhibition and Apoptosis independent cell death. Asian Pac J Cancer Prev 2014; 15: 1937-1941.

[10] Kim BY, Cui ZG, Lee SR, Kim SJ, Kang HK, Lee YK, et al. Effects of Asparagus officinalis extracts on liver cell toxicity and ethanol metabolism. J Food Sci 2009; 74: 204-208.

[11]Negi JS, Singh P, Joshi GP, Rawat MS, Bisht VK. Chemical constituents of asparagus. Pharmacogn Rev 2010; 4: 215-220.

[12] Karimi Jashni H, Kargar Jahromi H, Ghorbani Ranjbary A, Kargar Jahromi Z , Khabbaz Kherameh Z. Effects of aqueous extract from Asparagus officinalis L. roots on hypothalamic-pituitary-gonadal axis hormone levels and the number of ovarian follicles in adult rats Int J Reprod BioMed 2016; 14( 2): 75-80.

[13] Khanmohammadi Ghane F, Shahrouz R, Ahmadi A, Razi M. The protective effect of ethyl pyruvate on growth and atresia of ovarian follicles in cyclophosphamide-treated mice. Qom Univ Med Sci J 2015;9(3):1-11.

[14]Madan K, Bhardwaj P,Thareja S,Gupta SD, Saraya A. Oxidant stress and antioxidant status among patients with nonalcoholic fatty liver disease(NAFLD). J Clin Gastroenterol. 2006; 40:930-935.

[15] Orangi E, Ostad Rahimi A, Mahdavi R, Somi M, Tarzemani M. Oxidative stress-related parameters and antioxidant status in non-alcoholic fatty liver disease patients. Iranian Journal of Endocrinology and Metabolism 2011;12(5):558. (Persian)

[16] Zhu X, Zhang W, Zhao J, Wang J, Qu W. Hypolipidaemic and hepatoprotective effects of ethanolic and aqueous extracts from Asparagus officinalis L. by-products in mice fed a high-fat diet. J Sci Food Agric 2010; 90: 1129-1135.

[17]Farokhi F,Sadrkhanlou R, Hasanzadeh Sh, Sultanalinejad F.Morphological and morphometrical study of cyclophosphamide-induced changes in the ovary and uterus in 
the Syrian mice. Iranian Journal of Veterinary Research, University of Shiraz, 2007;8(4) :337-342.

[18] Tsai-Turton M, Luong BT, Tan Y, Luderer U. Cyclophosphamide-induced optosis in COV434 human granulosa cells involves oxidative stress and glutathione depletion. Toxicol Sci 2007;98(1):216-30.

[19] Nazari F, Johari H, Hemayatkhah Jahromi V, Kargar Jahromi H, Samani Jahromi E. The effect of the hydroalcoholic extract of ginseng on detoxifying cyclophosphamide in the ovary tissue of adult female rats. Par J Med Sci 2014;12(3):23-30.

[20] Amjadi GH,Mirzaii A,Tavakoli M,Saber V,Alie M.The effect of ginger hydroalcoholic essence on the ovarian hormones in the brest cancer rats by treatment cyclophosphamide in estrus cycle.International Journal of Fertility and Sterility,2012;6(1):148-149.

[21]Rezaie A , Roozbeh M, Goorani Nejad S, Najaf Zadeh Varzi H, Fatemi Tabatabaei R, Pour Mahdi Broojeni M. Effects of Tribulus Terrestris extract and Vitamin C on changes induced by cyclophosphamide in the rat ovary. Physiology and Pharmacology, 2013;17 (2): 194-203.

[22] Hewawasam RP, Jayatilaka KA, Pathirana C. Effect of Asparagus falcatus on acetaminophen toxicity in mice: a comparison of antioxidative effect with $\mathrm{N}$ - acetyl cysteine. J Diet Suppl. 2008;5(1):1-19.

[23] Zhang QH, Wu CF, Duan L, Yang JY. Protective effects of total saponins from stem and leaf of Panax ginseng against cyclophosphamide-induced genotoxicity and apoptosis in mouse bone marrow cells and peripheral lymphocyte cells. Food Chem Toxicol, 2008;46(1):293-302.

How to cite this article:

Jashni H K and Jahromi H K. Effects of palm pollen on folliculogenesis process after treatment with cyclophosphamide among rats. J. Fundam. Appl. Sci., 2016, 8(4S), 1998-2007. 